\title{
Electronic Health Record Implementation Strategies
}

\author{
Richard A. Warren \\ Walden University \\ Minneapolis MN, USA
}

\author{
Ify S. Diala \\ Walden University \\ Minneapolis MN, USA
}

\begin{abstract}
Adoption of electronic health records (EHR) systems in nonfederal acute care hospitals has increased, with adoption rates across the United States reaching as high as $94 \%$. Of the 330 plus acute care hospital EHR implementations in Texas, only $31 \%$ have completed attestation to Stage 2 of the meaningful use (MU) criteria. The purpose of this multiple case study was to explore strategies that hospital chief information officers (CIOs) used for the successful implementation of EHR. The target population consists of 3 hospitals CIOs from a multi-county region in North Central Texas who successfully implemented EHRs meeting Stage 2 MU criteria. The conceptual framework, for this research, was the technology acceptance model theory. The data were collected through semistructured interviews, member checking, review of the literature on the topic, and publicly available documents on the respective hospital websites. Using methodological triangulation of the data, 4 themes emerged from data analysis: EHR implementation strategies, overcoming resistance to technology acceptance, strategic alignment, and patient wellbeing. Participants identified implementation teams and informatics teams as a primary strategy for obtaining user engagement, ownership, and establishing a culture of acceptance to the technological changes. The application of the findings may contribute to social change by identifying the strategies hospital CIOs used for successful implementation of EHRs. Successful EHR implementation might provide positive social change by improving the quality of patient care, patient safety, security of personal health information, lowering health care cost, and improvements in the overall health of the general population.
\end{abstract}

Keywords: Electronic Health Records; EHR Implementations; Hospitals; Culture Acceptance; Technology.

\section{INTRODUCTION}

The United States has the largest health care system in the world, representing as much as $17.8 \%$ of the total Gross Domestic Production (GDP) in 2015 (Martin, Hartman, Washington, Catlin \& The National Health Expenditures Team, 2017). American health care expenditures continue to exceed cost inflation and GDP growth each year (Payne, Pressler, Sarker, \& Lussier, 2013). Despite the investment and escalating health care costs, there are shortcomings impacting the quality and efficiency of electronic health care record systems (Zhang et al., 2013). According to Payne et al. (2013), there is a continuing lack of management alignment of information systems (IS) and knowledge management technologies. Cognitive alignment of knowledge management systems with existing infrastructure is paramount in the migration to electronic health record (EHR) use and the articulation of the feasibility of EHR implementation for physicians (Dulipovici \& Robey, 2013). Although the United States is a highly industrialized nation, the United States remains behind other countries in developing an interoperable EHR infrastructure (Sao, Gupta, \& Gantz, 2013). Among the obstacles to the implementation of EHR systems are underdeveloped infrastructure and widespread concerns of consumers and medical professionals about privacy and security safeguards (Noblin et al., 2013). Technology and information systems abound in the United States, yet standardized, interoperable EHR systems provided by competing proprietary vendors are costly and could undermine patient centeredness (Zhang et al., 2016). Technical experts and technologists are available to help leaders in the United States become the preeminent leaders of EHR implementation. However, hospital leaders in the United States struggle with implementation timelines of EHRs, with some states significantly behind others in the rates of EHR adoption (Sao et al., 2013). The focus of this study was on exploring strategies hospital CIOs in Texas used for the successful implementation of EHR systems.

\section{PROBLEM \& PURPOSE OF THE STUDY}

Adoption of EHR systems in nonfederal acute care hospitals has increased since 2012 across the United States, reaching adoption rates as high as 94\% (Henry, Pylypchuk, Searcy, \& Patel, 2016). Texas lags behind the rest of the country at $80 \%$, and of the 330 plus acute care hospitals in which EHRs were implemented, only $31 \%$ have completed attestation to Stage 2 of the MU criteria (Office of the National Coordinator for Health Information Technology, 2016). The general business problem was that the implementation of EHR systems in Texas is below the national levels, with potential penalties for failure in attestation to MU criteria, leading to lost profits and elevated health care costs. The specific business problem was that some hospital chief information officers (CIOs) in Texas lack information about strategies for successful implementation of EHR systems. The purpose of this qualitative multiple case study was to explore strategies hospital CIOs in Texas used for the successful implementation of EHR systems. The population for this study included 10 acute care hospitals where the successful implementation of EHRs occurred in a multicounty region of North Central Texas. The multiple case study included the investigation of three hospitals' CIOs of the 10 acute care hospitals' CIOs having met Stage 2 attestation of the ONC and CMS specifications of the MU certification standards. Potential benefits of this study to society include the expansion of efficient quality medical practices and reducing medical care costs. The implications for positive social change includes improvements in medical care leading to a healthier society with lower health care costs and higher quality of care (Burns, Dyer, \& Bailit, 2014). EHR improvements in medical care include rapid and economical medical diagnoses, less redundancy in diagnostic tests, and the potential reduced medical errors (Bailey et al., 2013). Data mining provides further social benefits through the discovery of new medical treatments, the convergent evolution of health information management, and career opportunities for health informatics 
specialists and IT professionals in health care settings (Gibson, Dixon, \& Abrams, 2015).

\section{DISCUSSIONS}

\subsection{Background of EHRs}

Business The history of electronic health records began in the 1960s with the first implementation of computerized patient medical records, which evolved into advanced EHR systems (Murphy-Abdoch \& Biedermann, 2014). Over the 50 years that followed the first implementation of computerized patient medical records, technology advances in computer innovations opened the floodgates for advancements in health care (Turk, 2015). Migration from paper documentation of patient data to digital forms of record keeping occurred through the use multiple software applications and standalone computer systems (Murphy-Abdoch \& Biedermann, 2014). Development of and demand for innovation in health care technology continued as a potential cost-saving and efficient practice that could benefit patients and their health care organizations (Kerwin, Leighton, Buch, Avezbadalov, \& Kianfar, 2016).

The demand for more efficient and affordable health care recordkeeping technology created an expanding ecosystem of vendor competition in sales of clinic-specific software (Liu \& Zhu, 2013). Liu and Zhu (2013) proposed a unique model of an integrated e-service with the interconnected process and data-oriented grids. The model tied together electronic medical services, records, and application services with implementation architecture, which Liu and Zhu developed and tested through a prototype. Liu and Zhu contributed to the advancement of proposed technology models for health care professionals. However, the authors also highlighted obstacles, such as the need for ongoing updates and economic motivation, inability to interface legacy systems with emerging technologies, lack of interoperability, and cognitive factors involved in adopting new technologies. The explosion of a variety of applications and clinical specific systems exacerbated the problem of non-interoperable data sources.

Arvidsson, Holmstrom, and Lyytinen (2014) argued that strategic blindness becomes detrimental when mistranslating strategic intent, poor communications ensues, and cognitive entrenchment prevails. Accordingly, through the 1980s, desktop computers contributed to further development of noninteroperable, standalone systems and software applications for specific clinical tasks (Murphy-Abdoch \& Biedermann, 2014). Legislative actions by Congress, enacting HIPAA in 1996, resulted in extended health insurance coverage and requirements for security of personal health information (Anthony et al., 2014). The governmental action forced health care providers to change the normal operating procedures concerning the protection of personal medical information (Brumen, Heričko, Sevčnikar, Završnik, \& Hölbl, 2013). To meet the demands of federally mandated implementation of EHRs, hospital administrators pursued adoption of related technologies without a clear understanding of the total-costof-ownership (Legoux, Leger, Robert, \& Boyer, 2014).

Implementation of EHRs is not an optional activity for hospital administrators and health care providers because of government legislation (Brumen et al., 2013). Hospital administrators have a stake in fulfilling their responsibility for implementation, patient care, and financial incentives (Boonstra et al., 2014). However, Eastaugh (2013) analyzed data from an independent firm's survey of hospital chief financial officers resulting in evidence of a lack of knowledge and strategy concerning total-cost-of-ownership. Eastaugh also suggested that selection of a vendor for EHR systems involved many variables, such as the number of required EHR support staff and salaries, estimated 10-year costs of operations, anticipated revenues increases or losses, and ongoing upgrade costs.

Developing a strategy that integrates the IT infrastructure with the hospital organization is essential to successful EHR implementation (Silverman, 2013). Both Eastaugh (2013) and Silverman (2013) emphasized the importance of organizational strategy alignment with information systems strategy. Functional structuring of business operations strategies with information systems strategies contributes to successful EHR implementation. Recommendations based on findings reported by Eastaugh and Silverman included ongoing research support to address the need for strategies for successful EHR implementation.

The selection of an IT vendor continues to challenge CIOs. Before the adoption of EHRs, directors and CIOs should consider a myriad of issues (Liebe, Hüsers, \& Hübner, 2015). Business leaders should consider several aspects of EHR technology: interoperability, financial requirements, customer accessibility, internal business processes, and the means for learning and training (Loukis \& Charalabidis, 2013). Health information technology integration, as described by Silverman (2013), requires careful structuring and thoughtful design to facilitate a variety of uses and to accommodate a variety of users.

Lack of interoperability of ill-conceived information systems undermines the business value of innovations (Hung, Chen, \& Wang, 2014). Loukis and Charalabidis (2013) analyzed IS data that indicated establishing interoperability increases the positive impact of communication technology and medical informatics on the financial performance of the organizations. As technologies continue to evolve, assuring interoperability of various departmental and organizational specific computer applications, with security and protection of health information, represent paramount concerns for health care leaders (Meigs \& Solomon, 2016; Rodrigues, de la Torre, Fernández, \& López-Coronado, 2013; Studeny \& Coustasse, 2014).

Anthony et al. (2014) provided a background of the U.S. health care systems, federal and state regulations, and laws while describing how the regulatory system affects health care. The emphasis of Anthony et al. research was in the personal health information regulatory compliance. Findings of the research indicated a variety of ways that hospital leadership implements or circumvents regulatory compliance. Anthony et al. argued that market environment and institutional logics impede standardized compliance. Furthermore, compliance is higher in the case of for-profit hospitals versus not-for-profit institutions (Appari et al., 2013). The conclusion is that organizational differences or changes affect the medical professionals as well as the leadership's strategies.

In their research on requirements set forth for compliance with the HITECH Act and Affordable Care Act, on the implementation of EHR and verification of MU, Appari et al. (2013) described inconsistent results. Specifically, Appari et al. found that implementation of EHRs that met a lower level of MU criteria obtained higher levels of baseline quality of care than those implementing higher levels of MU. The 
implication is that the acceptance of advanced EHRs requires time for diffusion of technology acceptance.

Enactment of the HITECH Act in 2009 also provided incentive funding for the implementation of EHRs, based on verification of meeting MU criteria (Emani et al., 2014). DesRoches, Aduet, Painter, and Donelan (2013) conducted a national survey of 1820 primary care physicians and specialists in office-based practices to determine the number of physicians who had a basic EHR system and met the MU criteria. The response rate was $60 \%$ from which a $43.5 \%$ of physicians reported having a basic EHR, and $9.8 \%$ met MU criteria (DesRoches et al., 2013). The authors concluded that few physicians could meet the requirements in early 2013. Additionally, physicians varied on their familiarity with MU processes and requirements for meeting MU criteria (AdlerMilstein et al., 2014). In conclusion, the pace of implementation was increasing while there was a continued concern with the ease of use.

A further concern for leadership is that simply replacing paper records with EHRs may fail to produce gains in quality and efficiency or the reduction in costs that EHRs have the potential to achieve (Emani et al., 2014). Ease of use is more likely to contribute to improving the potential effect of EHRs. For example, setting expectations too high is counterproductive and may lead to financial losses due to inadequate research and strategic planning (Appari et al., 2013). Indications are that technology implementation alone is likely, but not sufficient, to produce quality improvements.

Myriad factors contribute to success since each medical facility is unique suggesting that one size might not fit all (Abramson, McGinnis, Moore, \& Kaushal, 2014; Meeks et al., 2014). Consequently, specific strategies might have varying success from one facility to another. CIOs and hospital leadership responsible for managing the implementation of EHRs have a stake in successfully guiding the processes and procedures (Gellert et al., 2015). Strategies for implementation involve consideration of domains, human factors, and financial implications, requiring knowledge and understanding of the complexities of the health care industry and specific clinical settings (Wu, Straub, \& Liang, 2015). Strategic alignment of multiple domains within the organizational structure may enhance the overall health care system.

\subsection{Barriers to EHR Adoption}

Acceptance of advanced and innovative technologies is a common phenomenon (King, Patel, Jamoom \& Furukawa, 2014). Although implementation of EHRs provides positive performance factor benefits to health care providers, there are obstacles hindering the process (Boonstra et al., 2014). In their systematic review and analysis, Boonstra et al. (2014) identified 19 frameworks for mitigating issues associated with EHR implementation. The three categories of the frameworks are (a) EHR context, (b) EHR content, and (c) EHR implementation process. Boonstra et al. recommended interventions for each in overcoming the obstacles to implementation.

Devkota and Devkota (2013) argued that expanding the use of EHR systems decreases health care costs and improves patient safety, efficiency, and overall organizational outcomes. However, obstacles to implementation, such as lack of funding and interoperability of current systems, retard the adoption of EHRs. Whereas Franzke, Wright, and Hautamaki
(2014) argued that usability is a major concern, Devkota and Devkota (2013) noted that patient care and safety are the beneficial outcomes that should be of concern to leaders. Bagyogo, Lapointe, and Bassellier (2014) claimed that the focus of leaders should be on EHR performance, overall technology potential, and user initiative.

User adaptation and ease of use affect efficiency potential of data-intense environments creating opportunities for electronic patient and provider interactions (Ancker et al., 2014). Otto and Nevo (2013) suggested that, along with concern for safety, there are other mitigating factors such as political and economic issues slowing the progress of EHR adoption. Physicians' perceptions and resistance to migrating to EHRs, cited by Otto and Nevo were a loss of control, provider attitude, financial negatives, and continuity of care as an obstacle to adoption. Jamoom, Patel, Furukawa, and King (2014) presented a contrasting view concerning what little knowledge exists about physicians' perspectives on EHR adoption and use; in their research, a comparison of the perspectives of adopters and nonadopters revealed similar results as Otto and Nevo. The greatest obstacles perceived by both adopters and nonadopters included purchase cost and productivity (Jamoom et al., 2014; Otto \& Nevo, 2013). Compared to other groups studied, the nonadopters showed considerably more concern with various national health IT policies and financial incentives or penalties for electronic record usage as major factors shaping their EHR adoption potentials.

King, Furukawa, and Buntin (2013) cited lower adoption rates in different geographic locations. King et al. studied EHR adoption rates in a low-income population part of the Midwest, another geographic area with a high population of low-income minorities in the Northeast, and a large metropolitan area in the American West. In contrast to the larger metropolitan area, the two underserved areas in the Midwest and Northeast had lower adoption rates (King et al., 2014). Reasons cited by King et al. for low adoption included limited access to advanced health care technology, organizational complexity, and less favorable business scenarios.

Struik et al. (2014) approached problems related to the slow adoption of EHRs in a discrete choice experiment. The experiment occurred to address the following previously identified barriers in the literature: data entry hardware, technical support, the attitude of the department head, performance feedback, flexibility of interface, and decision support. The perspectives of nurses and physicians were that flexibility of the interface was the factor of highest importance. The results aligned with the TAM, as ease of use, represented an enhancer to the acceptance of technology, described by Davis (1989). Struik et al. demonstrated the internal and external influences on the implementation of health information technologies, and then discussed the social implications affecting organizations.

Cresswell and Sheikh (2013) argued that although much research has covered the health care industry, organizational issues associated with implementation strategies lack adequate research. Zhang et al. (2013) proclaimed that the health care industry is much slower to adopt technology, in comparison to other industries, and there is a larger percentage of adoptions in administrative information technology versus clinical and strategic IT adoptions. Zhang et al. and Cresswell and Sheikh suggested organizational factors dominate as the most influential factors on adoption, requiring research attention. 


\subsubsection{Regulatory Influences}

Concern for the security of patient medical records and the safety of patients prompted legislative action resulting in signing HIPPA into law in 1996 (Anthony et al., 2014). The HITECH Act and American Recovery and Reinvestment Act of 2009 provided incentives to promote the adoption of EHRs and MU of health information technology (Sheikh, Sood, \& Bates, 2015). Passage of the Patient Protection and Affordable Care Act of 2010 introduced a far greater emphasis on federal regulations of the American health care industry (Bauer, Thielke, Katon, Unutzer, \& Arean 2014). Shaw, Asomugha, Conway, and Rein (2014) proclaimed enactment of the Patient Protection and Affordable Care Act is the greatest change in American health care policy since the 1960s. Legislation restraining discriminatory insurance practices, providing more affordable coverage and methods of reducing costs may lead to considerable benefits and coverage for an additional 25 million American citizens (Shaw et al., 2014).

Due to the pervasiveness of EHRs and health information exchanges, there is increased potential for improved health care. However, Ben-Assuli (2014) argued that serious concerns are legal and privacy issues. Despite these unresolved concerns, incentives provided through the HITECH Act for attesting to MU contributed to the increased adoption of EHRs (Adler-Milstein et al., 2013). AdlerMilstein et al. (2013) emphasized that hospitals ineligible for the federal MU incentives have extremely low adoption rates. MU eligible providers perform quite well with most scoring 90-100 on the 15 measures of MU (Wright, Feblowitz, Samal, McCoy, \& Sittig, 2014). The Centers for Medicare and Medicaid Services incentives of $\$ 30$ billion have been instrumental in the rapid increase of adoption (Mirani \& Harpalani, 2014). However, several states including Texas are slow in the adoption of EHRs (Charles et al., 2015).

\subsubsection{EHR Benefits}

Nationally, the beneficence of EHRs comes in different forms. Physicians' attest to the clinical benefits of providing enhanced patient care overall, ability to access patients' charts remotely, medical medication alerts, and critical lab values (King et al., 2014). In the research, King et al. performed a cross-sectional data examination of the 2011 Physician Workflow study, representative of office-based American physicians. The doctors' perspectives on the benefits of EHRs were that between $30 \%$ and $50 \%$ of physicians in the study stated clinical benefits were the ability to provide recommended care, appropriate tests, and enhanced patientprovider communications (King et al., 2014). However, Asan, Smith, and Montague (2014) studied 8 family practice physicians and 80 patients, leading to findings that physicians spent more time with the EHR screen than with paper records and less time looking at patients. Asan et al. claimed that their findings could be responsible for negative patient perceptions of physicians who use EHR, with implications for the design and adoption of related technologies.

Effective teamwork directly affects the quality of patient care. Properly aligned and implemented technologies can enhance professional health care teamwork (O'Malley, Draper, Gourevitch, Cross, \& Scholle, 2015). Gratez et al. (2014) examined whether primary team cohesion affects outpatient EHRs and clinician-rated care coordinated across delivery sites. Gratez et al. claimed that EHR might not have a positive benefit with less cohesive teams; effectiveness and beneficence depend on the users' proficiencies with the systems. From their study of 63 physicians and health care desk staff, O'Malley et al. (2015) claimed that EHRs could facilitate communication and task delegations of teams but could pose challenges to teamwork if there is a lack of integrated software, poor functionality and interoperability, and inadequate ease of use.

Other noted benefits of EHRs, as indicated by Haegerich, Sugerman, Annest, Klevens, and Baldwin (2014) include injury and error prevention through improved surveillance and monitoring of clinical treatments and outcomes. Hoffman and Podgurski (2013) similarly reported enhanced clinical outcomes from EHRs for the prevention, treatment, and monitoring of infectious diseases, disease outbreaks, and chronic illnesses. EHRs contribute to the rapid analysis of data transmitted electronically to public health authorities. Jaffe, Harold, Frieden, and Thomas (2014) also identified numerous ongoing improvements in health security, enhanced surveillance systems, medical countermeasures, and laboratory networks designed to improve the ability to respond to day-to-day medical issues and emerging health issues.

The ability to store a massive amount of medical data improves continuously yet the accessing data could be challenging depending on the type of database (Wang, Min, Wang, Lu, \& Duan, 2015). Communications after health care visits, referrals for specialists or follow-up visits, access to medical records, review of lab results, and maintaining financial records are part of the benefits of EHR systems, which are essentially databases that scholars, such as Wang et al. (2015) continue to try to improve. The benefits of EHRs include the ability to establish a path for accessing relevant data for a variety of medical conditions, transitioning from paper to computers with the potential for reduced health care costs, improved patient care, and safety. However, scholars such as Wang et al. (2015) continue to work toward solutions to the challenges. Noblin et al. (2013) argued that increased numbers of physicians and hospital administrators implementing EHRs assume that the systems will contribute to enhanced safety, efficiency and improved quality of care. As noted, research is replete with analysis indicating that system designs will continue to evolve and continue to garner the beneficial aspects of EHR.

EHRs represented the conversion from paper to digital media to provide physicians, health care staff, and patients the opportunities to store entire medical records and historical data on accessible or mobile storage media (Tansel, 2013). As the patient travels so does the patient's medical record. During medical emergencies, instant access to the patient's medical records might be the difference between life and death. Terry (2013) argued similarly that advances in technology should improve patient health care.

However, Terry (2013), like O'Malley et al. (2015) and Asan et al. (2014), acknowledged drawbacks that accompany the benefits of EHRs. Issues with EHRs such as usability, technological limitations that impede interoperability and safety concerns cast doubt on current EHRs (Terry, 2013). Lee, Kuo, and Goodwin (2013) also highlighted the gap that appeared between expected and actual outcomes of the benefits of EHR implementation. EHRs are inherently expensive because of required infrastructure, electrical power requirements, climatic control, equipment costs, software costs, IT personnel costs, and ongoing updates and maintenance costs. Dey, Sinha, and Thirumalai (2013) suggested that increasing the level of electronic medical records technology might not be beneficial to all providers, based on organizational, environmental, and financial limitations of the providers. 


\subsubsection{Cost of EHRs}

EHR system costs can run into millions of dollars depending on the size and complexity of services provided by hospital organizations (Smith, Bradley, Bichescu, \& Tremblay, 2013). Financial decisions made by hospital administrators determine strategies CIO's can pursue in the implementation of EHRs. Investing in information systems is a serious undertaking, but there is a lack of knowledge about how CEOs determine IS funding allocations among other competing expenses for business priorities (Salge et al., 2015). Wang et al. (2015) noted that data conversion and maintenance processes are costly regarding both time and money that escalates with greater numbers of record additions. Therefore, failure to discern the value of EHR implementation might be cause for hesitancy on the part of hospital CEOs' desire to allocate resources.

Determining the value creation by IT investment is difficult due to the differences between health care and other industries. Sherer (2014) argued that there is mixed evidence concerning the value created by health IT systems and implementation costs become difficult to determine because government incentives programs skew results. Adding to the overall cost of IT systems, management must consider the costs of IT employees. Kruse, Mileski, Alaytsev, Carol, and Williams (2015) reported that barriers to EHR adoption include escalating costs, users' negative perceptions, lack of sufficient implementation planning, and lack of proper training requiring potentially expensive support staff or extended education costs. Human resource managers confronted with demands for qualified IT staff work within the confines of budgets for the costs of technical training and IT personnel (Wang \& Kaarst-Brown, 2014). As the expansion of technology increases, the need for technologically perceptive human capital also increases (Majumdar, 2014). CIOs obligate funds for EHR infrastructure and the intellectual capital to maintain the increasingly complex innovative technologies; organizations investing in EHR sustainability initiatives must expect increased budgetary expenses (Majumdar, 2014). Terry (2013) estimated that investments in health informatics and technology infrastructure costs approximately $\$ 60,000$ per bed.

According to the Organization for Economic Co-operation and Development, the United States cost of public health per person exceeds five other high-spending countries examined by Lorenzoni, Belloni, and Sassi (2014). Additionally, the total overall costs of health care in America increased to $\$ 2.8$ trillion in 2012 (Jaffee \& Frieden, 2014). Researching the financial IT investment, Strong et al. (2014) reported falling short of the expected results of lowered costs, higher efficiency, and patient and provider satisfaction from IT medical record advances. In contrast to Strong et al. (2014), Smith et al. (2013) emphasized that sophisticated electronic medical record system investments result in improved financial performance and increased employee productivity. In agreement with Smith et al. 2013, Bardhan and Thouin (2013) reported a positive relationship between reduced costs and improved care with the implementation of financial and clinical information systems. In light of mixed research results, the significance of the EHR problems, and the relative infancy of their applications, a call for ongoing research persists in the literature, concerning the viability of EHRs, cost-effectiveness, and improved health care resulting from EHR investments (Bardhan \& Thouin, 2013; Salge et al., 2015; Terry, 2013).

\subsection{Barriers to EHRs Implementation}

From ongoing research about physicians' perspectives on EHR adoption, the most emphasized barriers to EHR adoption are costs, productivity loss, and decreased interactions with patients due to increased interactions with computers (Bae \& Encinosa, 2016; Jamoom et al., 2014; Kruse et al., 2015). Physicians perceived the use of EHRs to be time-consuming activities affecting the amount of time available for patient interaction (Bensefi \& Zarrad, 2014). The majority of physicians who participated in EHR studies felt pressure to complete digital forms that detract from time providing health care to the patient (Meigs \& Solomon, 2016). Discounting productivity loss, as familiarization increases, proficiency of the user decreases the time associated with the digital input (Bae \& Encinosa, 2016). Social-technical acceptance, environmental impact, and organizational factors appear to be among the major factors influencing adoption of information technology (Zhang et al., 2013).

The literature reflects the reality of existing barriers to the adoption of informatics for most industries. However, there is a need to consider factors concerning the protection and security of patient data (Turk, 2015). The U.S. Congress passed ARRA, expanding HIPAA, with specific guideline and safeguards intended to protect the patients' records (Bredfeldt et al., 2013). However, breaches still occur due to the human factor when dealing with large digital data sources, with the potential for hacking and lack of adherence to the guiding principles (Turk, 2014). Across diverse health care settings throughout the world, there are concerns from patients and the public about the security and privacy of their EHR information (Papoutsi et al., 2015). Training increases knowledge and proficiency of system users and can help users understand privacy and security risks and concerns (Kim, 2013). Constant assessments of users' performances and procedures are paramount to mitigating risks, such as commercial exploitation, lack of accountability, data inaccuracies, prejudices, and inequalities in health care provision (Colligan, Potts, Finn, \& Sinkin, 2015; Papoutsi et al., 2015).

Colligan et al. (2015) reported that cognitive workload associated with EHR usage increases for nurses. Although Colligan et al. warned against generalizing a one-size-fits-all conclusion about how EHR usage affects every person who uses the technology, the authors did explain that as user experience increases cognitive workload tends to decrease. User workload, cognitive processes required, and investment of time in training and usage may also vary depending on how many systems a user must learn, complicated by a general lack of interoperability among different (Loukis \& Charlabidis, 2013). Interoperable information systems in the health care IT industry are uncommon and appears to be one of the most frequently cited problems with health care technology (Slight et al., 2015). There is a growing number of vendors and suppliers of certified health care information systems (Yeung, Jadad, \& Shachak, 2013). Consequently, it is beneficial for adopters of IS in establishing an infrastructure focused on interoperability within the organization and with emphasis on collaborators such as customers, the organization supply chain, and business partners (Loukis \& Charalabidis, 2013). Interoperability in the case of hospital EHRs is a barrier to implementation (Kruse et al., 2014). 


\section{METHODOLOGY}

This qualitative, multiple case study involved three CIOs from 10 acute care hospitals in a multicounty region of North Central Texas who have implemented EHRs successfully meeting Stage 2 of the ONC and CMS specifications of the MU certification standards. Purposeful sampling for participants from the population who are information-rich subjects heightened the trustworthiness of this study. Purposeful selection of 3 CIOs possessing expertise, qualifications, and experience of having been successful in EHR implementation fulfills the requirement. Data collection processes involved face-to-face semistructured interviews with open-ended questions, outside of the hospital setting, at a private, quiet location mutually accessible to the researcher and participant. Another data collection technique used to gather participant data included publicly available documents, such as the documents and data maintained by the Definitive Healthcare Network, Government agencies, and hospitals to understand the strategies that can be successful for EHR implementation. Corroborating evidence may stem from documents about information system architecture, historical data, illustrative diagrams, detailed specifications, and implementation timelines. Analysis of data included, Yin's (2011) five-phase logical and sequential process: a) compiling, (b) disassembling, (c) reassembling, (d) interpreting, and (e) concluding. NVivo 11 qualitative data analysis software was used because it is used to generate graphs and charts that can add clarity by the graphic representations conducive to a better understanding of findings.

\section{FINDINGS AND RESULTS}

Findings from this study resulted to four main themes from the data collection and analysis:

\subsubsection{Emergent Theme 1: EHR Implementation Strategies}

The overall impetus was that governmental directives were not optional and that EHRs were inevitable; without them, the organization would suffer financially. The first decisions that all the participants referred to was that there were joint decisions by the board of directors, CEOs, and CIOs to begin the process of EHR implementation. All participants confirmed that, as a business factor, the board of directors and upper management were supportive of the financial investment required to reach their organizational goals. In alignment with the TAM framework, $100 \%$ of the participants admitted expectations of resistance to change and acceptance of the technology changes imposed upon staff, nurses, and doctors. Each of the participants referred to several strategies for implementation of the EHRs, with similar approaches directly supporting the strategies and aligning with the organizational strategy.

\subsubsection{Emergent Theme 2: Obstacles to Technology Acceptance}

All of the participants referred to the need to obtain user support and acceptance of the forthcoming technology changes associated with EHR implementation. A common practice emerged from the participants' responses: that of developing an implementation team of multilevel employees. Without user acceptance, other implementation strategies might incur opposition at each stage of the process. To that end, each participant developed their implementation team as the primary tool for overcoming the expected resistance to technology changes. All participants referred to the need to incorporate strategies for overcoming the obstacles to the acceptance of new technology. The consensus was that by identifying obstacles to the EHR implementation and ways to overcome obstacles may lead to successfully aligned strategies for improving acceptance.

\subsubsection{Emergent Theme 3: Strategic Alignment}

All the participants referred to the fact that what works for some organizations may not necessarily work in other organizations. Each hospital organization studied was different in many aspects, size, the number of employees, the number of beds, the number of individual clinics, and geographic location. The common ground for all the participant is that alignment of organizational strategy and EHR implementation is an ongoing challenge. Existing research confirms the participants' assertions in that identifying obstacles to technology acceptance and ways to overcome obstacles might lead to successfully aligned strategies for improving acceptance of the change and new technology.

\subsubsection{Emergent Theme 4: Patient Wellbeing}

All participants referred to potential benefits because of EHR implementation. The repeated occurrence of the keywords in the participants' responses identified the fourth major theme of improved patient well-being. The theme identified is a primary reason for governmental mandates for EHR implementation. The recurrence of the three terms led to three sub-themes contributing to improved patient well-being. All participants referred to the resulting benefits as improved patient health care, patient safety, and security of medical records. Patient care and safety are the beneficial outcomes for concerns of IT leaders. The participants' hospital websites corroborate responses provided during interviews and member checking procedures.

\section{CONCLUSION}

Successful implementation of EHRs, which meet the MU criteria, is a very challenging undertaking. The larger the organization, the greater the challenge due to the number of individual clinical applications there are to integrate into the EHR system. Hospital leaders understand the importance that information technology and other technologies contribute to the improvement in patient healthcare while reducing the overall cost of providing that care. Successful EHR system implementation is expensive and carries an ongoing cost with continual updates. Therefore, CIOs must have the full support of hospital leadership in financial matters, administratively, and organizationally for successful implementation. The overall stated goal of the participants was to meet the MU criteria as set forth by the ONC. What followed was numerous additional strategies to comply with the regulatory requirements otherwise face penalties equated in reduced reimbursements for medical services from the Center for Medicare and Medicaid Services (Adler-Milstein et al., 2013). Findings of this study indicate that strategies or methods used for successful EHR implementations are common sense 
approaches to overcoming resistance to change whether it be technology or changes in procedural practices. All participants confirmed that knowing the employees' perceptions and fears of the technology changes, guides the strategies required to overcoming the obstacles. Users must determine the ease of use and usefulness of the technology in verifying the success of overcoming resistance to technology acceptance (Davis, 1989). The strategies applied by the CIOs in this study such, as the implementation team and informatics team were instrumental in overcoming the resistance to technology acceptance. Identifying the obstacles to resistance enhances the potential for developing solutions to overcome the same.

\section{REFERENCES}

[1] Martin, A., Hartman, M., Washington, B., Catlin, A., \& The National Health Expenditure Accounts Team, 2017). National health spending: Faster growth in 2015 as coverage expands and utilization increases. Health Affairs, 36, 1166-1176. doi:1377/hlthaff.2016.1330

[2] Payne, P., Pressler, T. R., Sarkar, I. N., \& Lussier, Y. (2013). People, organizational, and leadership factors impacting informatics support for clinical and transitional research. Biomedical Central Medical Informatics and Decision Making, 13(20), 1-12. doi:10.1186/1472-6947-13-20

[3] Zhang, N. J., Seblega, B., Wan, T., Unruh, L., Agiro, A., \& Miao, L. (2013). Health information technology adoption in U.S. acute care hospitals. Journal of Medical Systems, 37(9907), 1-9. doi:10.1007/s10916-012-9907-2

[4] Dulipovici, A., \& Robey, D. (2013). Strategic alignment and misalignment of knowledge management systems: A social representation perspective. Journal of Management Information Systems, 29(4), 103-126. doi:10.2753/MIS0742-1222290404

[5] Sao, D., Gupta, A., \& Gantz, D. A. (2013). Interoperable electronic health care record: A case for adoption of a national standard to stem the ongoing health care crisis. Journal of Legal Medicine, 35, 55-90. doi:10.1080/01947648.2013.768153

[6] Noblin, A., Cortelyou-Ward, K., Cantiello, J., Breyer, T., Oliveira, L., Dangiolo, M., ... Berman, S. (2013). EHR implementation in a new clinic: A case study of clinician perceptions. Journal of Medical Systems, 37, 1-5. doi:10.1007/s10916-013-9955-2

[7] Henry, J., Pylypchuk, Y., Searcy T. \& Patel V. (May 2016). Adoption of Electronic Health Record Systems among U.S. Non-Federal Acute Care Hospitals: 20082015. ONC Data Brief, no.35. Office of the National Coordinator for Health Information Technology: Washington DC

[8] Office of the National Coordinator for Health Information Technology. (2016). Health IT dashboard. Washington, DC: United States Department of Health and Human Services. Retrieved from https://dashboard.healthit.gov

[9] Burns, M., Dyer, M., \& Bailit, M. (2014). Reducing overuse and misuse: State strategies to improve quality and cost of health care. Princeton, NJ: Robert Wood Johnson Foundation.
[10] Bailey, L. F. (2014). The origin and success of qualitative research. International Journal of Market Research, 56(2), 167-184. doi:10.2501/IJMR-2014-013

[11] Gibson, C. J., Dixon, B. E., \& Abrams, K. (2015). Convergent evolution of health information management and health informatics: A perspective on the future of information professionals in health care. Applied Clinical Informatics, 6(1), 163-184. doi:10.4338/ACI-2014-09RA-0077

[12] Murphy-Abdouch, K., \& Biedermann, S. (2014). The electronic health record. In S. H. Fenton, \& S. Biedermann, Introduction to healthcare informatics (pp. 25-70). Chicago, IL: AHIMA Press

[13] Turk, M. (2015). Electronic health records: How to suture the gap between privacy and efficient delivery of healthcare. Brooklyn Law Review, 80, 565-597. Retrieved from https://www.brooklaw.edu

[14] Kerwin, T., Leighton, H., Buch, K., Avezbadalov, A., \& Kianfar, H. (2016). The effect of adoption of an electronic health record on duplicate testing. Cardiology Research and Practice, 2016, 1-5. doi:10.1155/2016/1950191

[15] Liu, L., \& Zhu, D. (2013). An integrated e-service model for electronic medical records. Information Systems EBusiness Management, 11, 161-183. doi:10.1007/s10257-012-0188-6

[16] Arvidsson, V., Holmstrom, J., \& Lyytinen, K. (2014). Information systems use as strategy practice: A multidimensional view of strategic information system implementation and use. Journal of Strategic Information Systems, 23, 45-61. doi:10.1016/j.jsis.2014.004

[17] Anthony, D. L., Appari, A., \& Johnson, M. E. (2014). Institutionalizing HIPAA compliance: Organizations and competing logics in U.S. health care. Health Care $\begin{array}{lll}\text { Systems, } & \text { 55(1), } & \text { 108-124. }\end{array}$ doi: $10.1177 / 0022146513520431$

[18] Brumen, B., Heričko, M., Sevčnikar, A., Završnik, J., \& Hölbl, M. (2013). Outsourcing medical data analyses: Can technology overcome legal, privacy, and confidentiality issues? Journal of Medical Internet Research, 15, 283-295. doi:10.2196/jmir.2471

[19] Legoux, R., Leger, P. M., Robert, J., \& Boyer, M. (2014). Confirmation biases in the financial analysis of IT investment. Journal of the Association for Information Systems, 15(1), 33-52. Retrieved from http://aisel.aisnet.org/jais/

[20] Boonstra, A., Versluis, A., \& Vos, J. F. J. (2014). Implementing electronic health records in hospitals: A systematic literature review. Biomedical Central Health Services Research, 14, 370-384. doi:10.1186/1472-696314-370

[21] Eastaugh, S. R. (2013). The total cost of EHR ownership. Health care Financial Management, 67(2), 66-70. Retrieved from https://www.hfma.org/hfm

[22] Silverman, R. D. (2013). EHRs, EMRs, and health information technology: To meaningful use and beyond. Journal of Legal Medicine, 34(1), 1-6. doi:10.1080/01947648.2013.768134

[23] Liebe, J., Hüsers, J., \& Hübner, U. (2015). Investigating the roots of successful IT adoption processes: An empirical study exploring the shared awareness- 
knowledge of Directors of Nursing and Chief Information Officers. BMC Medical Informatics and Decision Making, 16(1), 10-24. doi:10.1186/s12911-016-0244-0

[24] Loukis, E. N., \& Charalabidis, Y. K. (2013). An empirical investigation of information systems interoperability business value in European firms. Computers in Industry, 64, 412-420. doi:10.1016/j.compind.2013.01.005

[25] Hung, S., Chen, C., \& Wang, K. (2014). Critical success factors for the implementation of integrated healthcare information systems projects: An organizational fit perspective. Communications of the Association for Information Systems, 34, 775-796. Retrieved from http://aisel.aisnet.org/cais/

[26] Meigs, S. L., \& Solomon, M. (2016). Electronic health record use a bitter pill for many physicians. Perspectives in Health Information Management, 13(1), 1-4. Retrieved from http://perspectives.ahima.org/

[27] Rodrigues, J., de la Torre, I., Fernández, G., \& LópezCoronado, M. (2013). Analysis of the security and privacy requirements of cloud-based electronic health records systems. Journal of Medical Internet Research, 15(8), 186-191. doi:10.2196/jmir.2494

[28] Studeny, J., \& Coustasse, A. (2014). Personal health records: Is rapid adoption hindering interoperability? Perspectives in Health Information Management, 11(2), 1-5. Retrieved from http://perspectives.ahima.org/

[29] Appari, A., Johnson, M. E., \& Anthony, D. L. (2013). Meeting meaningful use of electronic health record systems and process quality of care: Evidence from a panel data analysis of U.S. acute-care hospitals. Health Services Research, 48, 354-375. doi:10.1111/j.1475-6773.2012.01448.x

[30] Emani, S., Ting, D. Y., Healey, M., Lipsitz, S. R., Karson, A. S., Einbinder, J. S., ...Bates, D. W. (2014). Physician beliefs about the impact of meaningful use of the EHR: A cross-sectional study. Applied Clinical Informatics, 5, 789-801. doi:10.4338/ACI-2014-05-RA0050

[31] DesRoches, C. M., Audet, A., Painter, M., \& Donelan, K. (2013). Meeting meaningful use criteria and managing patient populations: A national survey of practicing physicians. Annals of Internal Medicine, 158, 791-799.

doi:10.7326/0003-4819-158-11-201306040-00003

[32] Adler-Milstein, J., Slazberg, C., Franz, C., Orav, E. J., \& Bates, D. W. (2013). The impact of electronic health records on ambulatory costs among Medicaid beneficiaries. Medicare Medicaid Research Review, 3(1), e1-e13. doi:10.5600/mmrr.003.02.a03

[33] Abramson, E. L., McGinnis, S., Moore, J., \& Kaushal, R. (2014). A statewide assessment of electronic health record adoption and health information exchange among nursing homes. Health Services Research, 49, 361-372. doi:10.1111/1475-6773.12137

[34] Meeks, D. W., Smith, M. W., Taylor, L., Sittig, D. F., Scott, J. M., \& Singh, H. (2014). An analysis of electronic health record-related patient safety concerns. Journal of the American Medical Informatics Association, 21, 1053-1059. doi:10.1136/amiajnl-2013002578
[35] Gellert, G. A., Hill, V., Bruner, K., Maciaz, G., Saucedo, L., Catzoela, L., ... Webster, S. L. (2015). Successful implementation of clinical information technology: Seven key lessons from CPOE. Applied Clinical Informatics, 6 , doi:10.4338/ACI-2015-06-SOA-0067

[36] Wu, S. P., Straub, D. W., \& Liang, T. (2015). How information technology governance mechanisms and strategic alignment influence organizational performance: Insights from a matched survey of business and IT managers. MIS Quarterly, 39, 497-518. Retrieved from http://www.misq.org

[37] King, J., Patel, V., Jamoom, E. W., \& Furukawa, M. F. (2014). Clinical benefits of electronic health record use: National findings. Health Services Research, 49, 392404. doi:10.1111/1475-6773.12135

[38] Devkota, B., \& Devkota A. (2013). Electronic health records: Advantages of use and barriers to adoption. Health Renaissance, 11(3), 181-184. doi:10.3126/hren.v11i3.9629

[39] Franzke, M., Wright, S., \& Hautamaki, B. (2014). The intersection of IT and human factors: Summative testing in safety-enhanced EHR design. Biomedical Instrumentation \& Technology, 47(2), 1-6. doi:10.2345/0899-8205-47.s2.54

[40] Bagayogo, F. F., Lapointe, L., \& Bassellier, G. (2014). Enhanced use of IT: A new perspective on post-adoption. Journal of the Association for Information Systems, 15, 361-387. Retrieved from http://aisel.aisnet.org/jais/

[41] Ancker, J. S., Kern, L. M., Edwards, A., Nosal, S., Stein, D. M., \& Hauser, D. (2014). How is the electronic health record being used? Use of EHR data to assess physicianlevel variability in technology use. Journal of the American Medical Informatics Association, 21, 10011008. doi:10.1136/amiajnl-2013-002627

[42] Otto, P., \& Nevo, D. (2013). Electronic health records: A simulation model to measure the adoption rate from policy interventions. Journal of Enterprise Information Management, 26(1/2), 165-182. doi:10.1108/17410391311289613

[43] Jamoom, E. W., Patel, V., Furukawa, M. F., \& King, J. (2014). EHR adopters vs. non-adopters: Impacts of, barriers to, and federal initiatives for EHR adoption. Healthcare, 2(1), 33-39. doi:10.1016/j.hjdsi.2013.12.004

[44] King, J., Furukawa, M. F., \& Buntin, M. B. (2013). Geographic variation in ambulatory electronic health record adoption: Implications for underserved communities. Health Services Research, 48, 2037-2059. doi:10.1111/1475-6773.12078

[45] Struik, M. H., Koster, F., Schuit, A. J., Nugteren, R., Veldwijk, J., \& Lambooij, M. S. (2014). The preferences of users of electronic medical records in hospitals: Quantifying the relative importance of barriers and facilitators to an innovation. Implementation Science, 9(69), 1-11. doi:10.1186/1748-5908-9-69

[46] Davis, F. D. (1989). Perceived usefulness, perceived ease of use, and user acceptance of information technology. MIS Quarterly, 13, 319-340. doi:10.2307/249008

[47] Cresswell, K., \& Sheikh, A. (2013). Organizational issues in the implementation and adoption of health information technology innovations: An interpretative 
review. International Journal of Medical Informatics, 82(5), e73-86. doi:10.1016/j.ijmedinf.2012.10.007

[48] Sheikh, A., Sood, H. S., \& Bates, D. W. (2015). Leveraging health information technology to achieve the "triple aim" of health care reform. Journal of the American Medical Informatics Association, 22, 849-856. doi:10.1093/jamia/ocv022

[49] Bauer, A. M., Thielke, S. M., Katon, W., Unutzer, J., \& Arean, P. (2014). Aligning health information technologies with effective service delivery models to improve chronic disease care. Preventive Medicine 66, 167-177. doi:10.1016/j.ypmed.2014.06.017

[50] Shaw, F. E., Asomugha, C. N., Conway, P. H., \& Rein, A. S. (2014). The patient protection and affordable care act: Opportunities for prevention and public health. Lance, 384, 75-82. doi:10.1016/s0140-6736(14)60259-2

[51] Ben-Assuli, O. (2015). Electronic health records, adoption, quality of care, legal, and privacy issues and their implementation in emergency departments. Health Policy, 119(3), 287-297. doi:10.1016/j.healthpol.2014.11.014

[52] Wright, A., Feblowitz, J., Samal, L., McCoy, A. B., \& Sittig, D. F. (2014). The Medicare electronic health record incentive program: Provider performance on core and menu measures. Health Services Research 49, 325346. doi:10.1111/1475-6773.12134

[53] Mirani, R., \& Harpalani, A. (2014). The Medicare electronic health records (EHR) incentive program: Firstyear adoption response from inpatient hospitals. Journal of Organizational Computing and Electronic Commerce, 24, 388-401. doi:10.1080/10919392.2014.956601

[54] Charles, D., Gabriel, M., \& Searcy T. (2015). Adoption of electronic health record systems among U.S. nonfederal acute care hospitals: 2008-2014 ONC Data Brief, No. 23. Washington, DC: Office of the National Coordinator for Health Information Technology, Government Printing Office.

[55] King, J., Patel, V., Jamoom, E. W., \& Furukawa, M. F. (2014). Clinical benefits of electronic health record use: National findings. Health Services Research, 49, 392404. doi:10.1111/1475-6773.12135

[56] Asan, O., Smith, P., \& Montague, E. (2014). More screen time, less face time: Implications for EHR design. Journal of Evaluation in Clinical Practice, 20, 896-901. doi:10.1111/jep.12182

[57] O’Malley, A. S., Draper, K., Gourevitch, R., Cross, D. A., \& Scholle, S. H. (2015). Electronic health records and support for primary care teamwork. Journal of the American Medical Informatics Association, 22, 426-434. doi.org/10.1093/jamia/ocu029

[58] Graetz, I., Reed, M., Shortell, S. M., Rundall, T. G., Bellows, J., \& Hsu, J. (2014). The association between EHRs and care coordination varies by team cohesion. Health Services Research, 49, 438-452. doi:10.1111/1475-6773.12136

[59] Haegerich, T. M., Sugerman, D. D., Annest, J. L., Klevens, J., \& Baldwin, G. T. (2015). Improving injury prevention through health information technology. American Journal of Preventive Medicine, 48(2), 219228. doi:10.1016/j.amepre.2014.08.018

[60] Hoffman, J. (2014). Preemption and the MLR provision of the affordable care act. American Journal of Law \&
Medicine, 40, 280-297. Retrieved from http://www.bu.edu/ajlm/

[61] Jaffe, H. W., \& Frieden, T. R. (2014). Improving health in the USA: Progress and challenges. The Lancet, 384(9937), 3-5.doi:10.1016/S0140-6736(14)61032-1

[62] Wang, L., Min, L., Wang, R., Lu, X., \& Duan, H. (2015). Archetype relational mapping: A practical open EHR persistence solution. Biomedical Central Medical Informatics and Decision Making, 15, 88-98. doi:10.1186/s12911-015-0212-0

[63] Tansel, A. (2013). Innovation through patient health records. Procedia Social and Behavioral Sciences, 75, 183-188. doi:10.1016/j.sbspro.2013.04.021

[64] Terry, N. P. (2013). Meaningful adoption: What we know or think we know about the financing, effectiveness, quality, and safety of electronic medical records. Journal of Legal Medicine, 34(1), 7-42. doi:10.1080/01947648.2013.768143

[65] Lee, J., Kuo, Y., \& Goodwin, J. S. (2013). The effect of electronic medical record adoption on outcomes in US hospitals. Bio Medical Central Health Services Research, 13, 1-7. doi:10.1186/1472-6963-13-39

[66] Dey, A., Sinha, K. K., \& Thrumalai, S. (2013). IT capability for health care delivery: Is more better? Journal of Service Research, 16, 326-340. doi:10.1177/1094670513478832

[67] Smith, A., Bradley, R. V., Bichescu, B. C., \& Tremblay, M. C. (2013). IT governance characteristics, electron medical records sophistication, and financial performance in U.S. hospitals: An empirical investigation. Decision Sciences Journal, 44, 483-516. doi:10.1111/deci.1219

[68] Salge, T. O., Kohli, R., \& Barrett, M. (2015). Investing in information systems: On the behavioral and institutional search mechanisms underpinning hospitals' investment decisions. MIS Quarterly, 39(1), 61-90. Retrieved from www.misq.org

[69] Wang, J., Ho, H., Chen, J., Chai, S., Tai, C., \& Chen, Y. (2015). Attitudes toward inter-hospital electronic patient record exchange: Discrepancies among physicians, medical record staff, and patients. Biomedical Central Health Services Research, 15, 264-279. doi:10.1186/s12913-015-0896-y

[70] Sherer, S. (2014). Advocating for action design research on IT value creation healthcare. Journal of the Association for Information Systems, 15, 860-878. Retrieved from http://aisel.aisnet.org/jais/

[71] Kruse, C. S., Mileski, M., Alaytsev, V., Carol, E., \& Williams, A. (2015). Adoption factors associated with electronic health record among long-term care facilities: A systematic review. BMJ Open, 5(1), 66-75. doi:10.1136/bmjopen-2014-006615

[72] Wang, C., \& Kaarst-Brown, M. (2014). The IT compensation challenges: Theorizing the balance among multi-level internal and external uncertainties. Journal of the Association for Information Systems, 15(3), 111-146. Retrieved from http://aisle.aisnet.org/jais

[73] Majumdar, S. K. (2014). Technology and wages: Why firms invest and what happens. Technology in Society, 39, 44-54. doi:10.1016/j.techsoc.2014.07.005

[74] Lorenzoni, L., Belloni, A., \& Sassi, F. (2014). Healthcare expenditure and health policy in the USA versus 
other high-spending OECD countries. Lancet, 384(9937), 83-92. doi:10.1016/s0140-6736(14)60571-7

[75] Strong, D. M., Johnson, S. A., Tulu, B., Trudel, J., Volkoff, O., Pelletier, L. R., ... Garber, L. (2014). A theory of organization-EHR affordance actualization. Journal of Computer Information Systems, 15(2), 55-85. Retrieved from http://aisle.aisnet.org/jais

[76] Smith, A., Bradley, R. V., Bichescu, B. C., \& Tremblay, M. C. (2013). IT governance characteristics, electron medical records sophistication, and financial performance in U.S. hospitals: An empirical investigation. Decision Sciences Journal, 44, 483-516. doi:10.1111/deci.1219

[77] Bardhan, I., R., \& Thouin, M. F. (2013). Health information technology and its impact on the quality and cost of healthcare delivery. Decision Support Systems, 55, 438-449. doi:10.1016/j.dss.2012.10.003

[78] Bae, J., \& Encinosa, W. E. (2016). National estimates of the impact of electronic health records on the workload of primary care physicians. Biomedical Central Health Services Research, 16, 172-194. doi:10.1186/s12913016-1422-6

[79] Bensefia, A., \& Zarrad, A. (2014). A proposed layered architecture to maintain privacy issues in electronic medical records. E-Health Telecommunication Systems and Networks, 3(4), 43-49. doi:10.4236/etsn.2014.34006

[80] Bredfeldt, C., Butani, A. L., Pardee, R., Hitz, P., Padmanabhan, S., \& Saylor, G. (2013). Managing personal health information in distributed research network environments. Biomedical Central Medical Informatics and Decision Making, 13(116), 1-7. doi:10.1186/1472-6947-13-116

[81] Papoutsi, C., Reed, J. E., Marston, C., Lewis, R., Majeed, A., \& Bell, D. (2015). Patient and public views about the security and privacy of Electronic Health Records (EHRs) in the UK: Results from a mixed methods study.
Biomedical Central Medical Informatics and Decision Making, 15, 86-102. doi:10.1186/s12911-015-0202-2.

[82] Kim M. (2013). Improving electronic health records training through usability evaluation in primary care. Journal of Health and Medical Informatics, 4(5), 110115. Retrieved from http://www.ijmijournal.com

[83] Colligan, L., Potts, H. W., Finn, C. T., \& Sinkin, R. A. (2015). Cognitive workload changes for nurses transitioning from a legacy system with paper documentation to a commercial electronic health record. International Journal of Medical Informatics, 84, 469476. doi:10.1016/j.ijmedinf.2015.03.003

[84] Loukis, E. N., \& Charalabidis, Y. K. (2013). An empirical investigation of information systems interoperability business value in European firms. Computers in Industry, 64, 412-420. doi:10.1016/j.compind.2013.01.005

[85] Slight, S. P., Berner, E. S., Galanter, W., Huff, S., Lambert, B. L., Lannon, C., ... Bates, D. W. (2015). Meaningful use of electronic health records: Experiences from the field and future opportunities. Journal of Medical Internet Research, 3(3), 30-44. doi:10.2196/medinform.4457

[86] Yeung, N. K., Jadad, A. R., \& Shachak, A. (2013). What do electronic health record vendors reveal About their products: An analysis of vendor websites. Journal of Medical Internet Research, 15(2), 36-58. doi:10.2196/jmir.2312

[87] Kruse, C. S., DeShazo, J., Kim, F., \& Fulton, L. (2014). Factors associated with adoption of health information technology: A conceptual model based on a systematic review. Journal of Medical Internet Research, 2(1), 1-10. doi:10.2196/medinform.3106

[88] Yin, R. K. (2011). Qualitative research from beginning to end. New York, NY: Guilford Press 